\title{
Semiology and radiology integration: a new trend in the teaching-learning process
}

\section{Integração semiologia e radiologia: nova tendência no processo de ensino e aprendizagem}

\author{
Rafaela Queiroz de Morais \\ Luciana Thurler Tedeschi' \\ Cristina Asvolinsque Pantaleão Fontes ${ }^{1}$ \\ Marcia Maria Sales dos Santos' ${ }^{1}$ \\ Maria Auxiliadora Nogueira Saad'

\begin{abstract}
rafaelagm13@gmail.com tedeschi.luciana@gmail.com

cristinasvolinsque@gmail.com

mmsales27@gmail.com

auxiliadorasaad@gmail.com
\end{abstract}

\begin{abstract}
Introduction: The development of clinical reasoning to diagnose diseases and order ancillary tests, such as radiology imaging, is based on historytaking and physical examination skills, which are developed during the semiology course.

Objective: We aimed to evaluate the results of the innovative integration of two courses in the medical curriculum at our institution: Medical Semiology and Clinical Radiology.

Methods: The sample consisted of 184 fifth-semester medical students attending the two courses simultaneously. Extra-class semiology-radiology sessions based on theoretical and practical topics integrating radiological images and semiological signs were conducted, and the results were assessed by applying a semi-structured questionnaire to the participants, in which all 18 items were rated on a scale from 0 (worst) to 10 (best). The normality hypothesis in score distribution was verified by the Kolmogorov-Smirnov test and the Shapiro-Wilk test. The distribution of the 18 scores were summarized by descriptive statistics and compared by Friedman's test, with post-hoc test in pairwise comparisons adjusted by Bonferroni test. Correlations between the scores were determined by Spearman's Rank Correlation Coefficients.
\end{abstract}

Results: The overall mean score for the semiology-radiology sessions was high (8.55). Students were satisfied with the selection of clinical cases (8.46) and found that the semiology-radiology sessions contributed to the development of their clinical reasoning (8.58).

Conclusion: Medical schools are facing new challenges in medical education. The innovative concept of Radiology-Semiology integrated teaching modality affects the students' self-perception ability to interpret radiological images and might be an educational strategy trend.

Keywords: Teaching; Semiology; Radiology; Integration.

\section{RESUMO}

Introdução: O desenvolvimento do raciocínio clínico para diagnosticar doenças e solicitar exames complementares, como os radiológicos, baseia-se na história e no exame físico, desenvolvidos durante o curso de Semiologia.

Objetivo: Nosso objetivo foi avaliar os resultados da integração inovadora de duas disciplinas no currículo médico em nossa instituição: Semiologia Médica e Radiologia Clínica.

Métodos: A amostra foi composta por 184 estudantes de Medicina do quinto semestre que participaram das duas disciplinas simultaneamente. Realizaram-se sessões extraclasse de semiologia e radiologia, baseadas em tópicos teóricos e práticos, integrando imagens radiológicas com sinais semiológicos. Avaliaram-se os resultados por meio da aplicação de um questionário semiestruturado aos participantes, no qual todos os 18 itens foram classificados em uma escala de 0 (pior) a 10 (melhor). A hipótese de normalidade na distribuição dos escores foi verificada pelos testes de KolmorovSmirnov e Shapiro-Wilk. As 18 distribuições de pontuação foram resumidas por estatística descritiva e comparadas pelo teste de Friedman, com teste post hoc em comparações pareadas ajustadas por Bonferroni. As correlações entre as pontuações foram determinadas pelos coeficientes de correlação de classificação de Spearman.

Resultados: $O$ escore médio geral para as sessões de semiologia e radiologia foi alto $(8,55)$. Os estudantes ficaram satisfeitos com a seleção de casos clínicos $(8,46)$ e descobriram que as sessões de semiologia-radiologia contribuíram para o desenvolvimento de seu raciocínio clínico $(8,58)$.

Conclusão: As escolas médicas enfrentam novos desafios na educação médica. O conceito inovador da modalidade de ensino integrado de radiologiasemiologia afeta a capacidade de autopercepção dos alunos para interpretar imagens radiológicas e pode ser uma tendência de estratégia educacional.

Palavras-chave: Ensino; Semiologia; Radiologia; Integração.

${ }^{1}$ Universidade Federal Fluminense, Niterói, Rio de Janeiro, Brasil.

Chief editor: Daniela Chiesa

Associate editor: Daniela Chiesa

Received on 02/17/20; Accepted on 11/08/20.

Evaluated by the double blind review process. 


\section{INTRODUCTION}

As early as in the fourth century BCE, Hippocrates and his disciples established the origins of Semiology, with the systematization of the clinical method by studying the signs and symptoms of diseases ${ }^{1}$. Their legacy is now the current medical interview model, which follows a logical and temporal sequence: history-taking, physical examination, ancillary testing, and diagnostic hypothesis generation. This sequence is the structure that allows the articulation between essential elements obtained by both semiology and medical knowledge ${ }^{2}$.

Similarly, in the post-Second World War period, the increasing demand for the development of medical technologies promoted the rapid ascension of Radiology, as well helped with its incorporation into medical practice, which is of particular relevance in the current health care environment ${ }^{3}$. Despite substantial changes in the structure of science-based curricula, such as practice-based and competency-based learning, the current teaching model of these disciplines remains largely unchanged from the traditional model ${ }^{4}$. The discussion about active methodologies, the diversity of teaching methods and the introduction of technological tools into the list of educational strategies is trending in the teaching-learning process ${ }^{5-7}$.

Currently, medical schools have been integrating problem and team-based learning into their curricula model. The multidisciplinary and multiprofessional approaches, involving humanistic, critical, and reflective aspects, are gaining acceptance as one of the possible options for new teaching strategies $^{8}$.

The aim of this study was to evaluate the results of the innovative integration of two courses in the medical curriculum at our institution: Medical Semiology and Clinical Radiology.

\section{MATERIALS AND METHODS}

This study included 184 fifth-semester medical students attending the Medical Semiology and Clinical Radiology courses simultaneously at our institution, with 141 participating in extra class activities. Our Semiology course aims to enhance bedside exam skills and Internal Medicine knowledge and our Radiology course aims to provide initial comprehension in adult presentations of basic diseases at imaging findings. Until 2015, the two courses had optative extra-class activities that were conducted separately by teaching assistants at the students' recess time, once a week. These sessions aimed to reinforce the practical application of the content taught in class by the teacher. From 2015 onwards, the extra-class activities of the two courses have been combined.

Briefly, after selecting patients from the inpatient units at the hospital affiliated with our institution, teaching assistants of the Medical Semiology course perform history-taking and physical examination with the students, who are divided into small groups, followed by a discussion of the patients' diagnostic radiological imaging test and findings. To this end, three teaching assistants of the Clinical Radiology course show the patients' $X$-ray, ultrasound, computed tomography, and magnetic resonance images to the students and discuss possible semiology findings and diagnostic hypotheses. During the course of the study, the teaching assistants also proposed a brief case-based group discussion before revealing the correct answer.

The imaging data were accessed through the Picture Archiving and Communication System (PACS), which stores all radiological data obtained at the hospital. The present study lasted two consecutive semesters; therefore, the collected data is related to the two classes of medical students exposed to the new methodology for the first time at the institution, from February to December 2016.

To evaluate the students' level of satisfaction with the new integrated extra-class semiology and radiology teaching methodology, an 18-question, semi-structured questionnaire was applied to the participants, in which all items were rated on a scale from 0 (worst) to 10 (best). The questions addressed the structure of the extra-class activity sessions, students satisfaction, characteristics and skills of the teaching assistants (such as performance, ability to integrate information, and availability), and self-assessment (Table 1).

The questionnaire included a subjective, open-ended request for suggestions to improve the integrated extra-class teaching methodology. Both normality tests (KolmogorovSmirnov test and Shapiro-Wilk test) resulted in p-values $<0.001$ for the distributions of all 18 scores. Thus, it was concluded that the distributions of the scores was not normal and the approach of the statistical analysis had to be nonparametric. The score distributions were summarized using descriptive statistics (Minimum, Maximum, 25 $5^{\text {th }}$ Percentile, $50^{\text {th }}$ Percentile, $75^{\text {th }}$ Percentile, Standard Deviation, and Coefficient of Variation). The distribution of the different scores was compared by Friedman's test, with post-hoc test in pairwise comparisons adjusted by Bonferroni test. Correlations between the scores were determined using Spearman's Rank Correlation Coefficients and the resulting correlations were classified as perfect if, strong if moderate if 0.70 , or weak if $\rho \leq 0.5$ (9). A $p$-value $<0.05$ was considered significant. Data were analyzed using SPSS 23.0 for Windows (9).

The study was approved by the institutional research ethics committee, under number 69900217.8.0000.5243. All procedures were in accordance with the 1964 Declaration of Helsinki and its later amendments or comparable ethical standards. Informed consent was obtained from all individual participants included in the study. 
Table 1. Questionnaire applied to medical students during combined Medical Semiology and Clinical Radiology extra-class activity sessions.
1. Overall score for the extra-class semiology-radiology sessions with teaching assistants.
2. How do you rate your performance in the sessions?
3. How do you rate the radiological study of the patient conducted by the teaching assistants (discussion of images on the computer)?

4. How do you rate the semiological study of the patient conducted by the teaching assistants (history-taking and physical examination)?

5. How do you rate the selection of clinical cases to be presented?

6. Ability of the teaching assistants to integrate images with the patient's clinical findings.

7. When the teaching assistants show the images, can you understand what is being shown?

8. When the teaching assistants perform history-taking and physical examination, can you understand what is being done?

9. Degree of support of the sessions for your learning of semiology.

10. Degree of support of the sessions for your learning of radiology.

11. Attendance to the semiology-radiology sessions.

12. How much have the sessions contributed to your clinical reasoning?

13. Level of satisfaction with the semiology-radiology sessions

14. Attention given by the teaching assistants when answering your questions.

15. Do you think you are able to evaluate radiological images?

16. Do you think you are able to examine a patient?

17. Do you think you are able to correlate clinical and radiological findings?

18. Exceeding expectations for the sessions.

\section{RESULTS}

Of the 184 students regularly enrolled in the Medical Semiology and Clinical Radiology courses in both semesters, 141 participated in extra class activities and answered the questionnaire, with a response rate of $76.63 \%$.

The results of the scores for each questionnaire item are summarized in Table 2. The overall mean score for the extraclass semiology-radiology sessions was 8.55 , median 9.0. The students' mean attendance at the sessions (item 11) was 8.40 , median 9.0, with a mean level of satisfaction of 8.10 , median 8.0. The three highest scores were associated with items 14 (Attention given by the teaching assistants when answering questions - mean score 9.57), 8 (History-taking and physical examination understanding - mean score 9.39) and 9 (Degree of support of the sessions for the learning of semiology- mean score 9.30). A total of 105 (74.47\%) students rated the attention given by the teaching assistants when answering their questions with the maximum score of 10 (mean score, 9.57, median 10.0). The lowest scores, but still satisfactory, were associated with the ability to interpret radiological images (mean score, 6.32; median 7.0) and to correlate clinical and radiological findings (mean score, 6.88; median 7.0). $80 \%$ of the students felt they were able to correlate clinical and radiological findings.

When comparing the distributions of the 18 scores by
Friedman's Test, the resulting $\mathrm{p}$-value was lower than 0.001 . Thus, we concluded that the distribution of the 18 scores was not the same. Various significant differences were found by the post hoc test for Friedman's pairwise comparisons, considering Bonferroni's correction in p-value. The score distribution of the item "Ability to evaluate radiological images" is significantly different than the distribution of almost all others items, except for the items "Degree of support of the sessions for the learning of radiology" and "Ability to correlate clinical and radiological findings". The score of the question "Ability to correlate clinical and radiological findings" has the same distribution of "Individual performance”, “Degree of support of the sessions for the learning of radiology" and "Ability to evaluate radiological images" scores and has a significantly different distribution when compared to the other items. The distribution of the scores for the items "Degree of support of the sessions for the learning of radiology" and "Ability to correlate clinical and radiological findings" was significantly different than the distribution of half of the items (items $1,4,5,6,8,9,12,14,18$ ). These items, of which scores showed the most significant differences when compared with other scores, are the items that showed the lowest means. The distribution of the scores of the items "Ability to examine a patient", "Level of satisfaction with the semiology-radiology sessions", and "Image understanding" are significantly different 
Table 2. Main Statistics of the Questionnaire Scores (Min: Minimum, Max: Maximum, P25: $25^{\text {th }}$ Percentile, P50: $50^{\text {th }}$ Percentile, P75: $75^{\text {th }}$ Percentile, SD: Standard Deviation, CV: Coefficient of Variation

\begin{tabular}{|c|c|c|c|c|c|c|c|c|}
\hline Item & Min & Max & $\mathbf{P 2 5}$ & P50 & P75 & Mean & SD & CV \\
\hline 1.Overall score ${ }^{\#}$ & 2.0 & 10.0 & 8.0 & 9.0 & 10.0 & 8.55 & 1.51 & 0.18 \\
\hline 2.Individual performance & 5.0 & 10.0 & 7.0 & 8.0 & 9.0 & 7.89 & 1.35 & 0.17 \\
\hline $\begin{array}{l}\text { 3. Radiological study of the patient conducted by the } \\
\text { teaching assistants }\end{array}$ & 0.0 & 10.0 & 7.0 & 8.0 & 10.0 & 8.23 & 1.67 & 0.20 \\
\hline $\begin{array}{l}\text { 4.Semiological study of the patient conducted by the } \\
\text { teaching assistants }\end{array}$ & 0.0 & 10.0 & 8.0 & 9.0 & 10.0 & 8.74 & 1.62 & 0.19 \\
\hline 5.Selection of clinical cases ${ }^{\S}$ & 0.0 & 10.0 & 8.0 & 9.0 & 10.0 & 8.47 & 2.01 & 0.24 \\
\hline $\begin{array}{l}\text { 6. Ability of the teaching assistants to integrate images } \\
\text { with the patient's clinical findings }{ }^{\S}\end{array}$ & 0.0 & 10.0 & 8.0 & 9.0 & 10.0 & 8.44 & 1.79 & 0.21 \\
\hline 7. Image understanding & 0.0 & 10.0 & 7.0 & 8.0 & 10.0 & 8.04 & 2.02 & 0.25 \\
\hline $\begin{array}{l}\text { 8. History-taking and physical examination } \\
\text { understanding }\end{array}$ & 3.0 & 10.0 & 9.0 & 10.0 & 10.0 & 9.39 & 0.97 & 0.10 \\
\hline $\begin{array}{l}\text { 9. Degree of support of the sessions for the learning of } \\
\text { semiology }\end{array}$ & 6.0 & 10.0 & 9.0 & 10.0 & 10.0 & 9.30 & 1.06 & 0.11 \\
\hline $\begin{array}{l}\text { 10. Degree of support of the sessions for the learning } \\
\text { of radiology }\end{array}$ & 0.0 & 10.0 & 6.0 & 8.0 & 9.0 & 7.30 & 2.24 & 0.31 \\
\hline 11. Attendance to the semiology-radiology sessions & 0.0 & 10.0 & 8.0 & 9.0 & 10.0 & 8.40 & 2.02 & 0.24 \\
\hline 12. Sessions' contribution to clinical reasoning & 0.0 & 10.0 & 8.0 & 9.0 & 10.0 & 8.58 & 1.54 & 0.18 \\
\hline $\begin{array}{l}\text { 13. Level of satisfaction with the semiology-radiology } \\
\text { sessions" }\end{array}$ & 0.0 & 10.0 & 7.0 & 8.0 & 10.0 & 8.10 & 1.73 & 0.21 \\
\hline $\begin{array}{l}\text { 14. Attention given by the teaching assistants when } \\
\text { answering questions }\end{array}$ & 5.0 & 10.0 & 9.0 & 10.0 & 10.0 & 9.57 & 0.87 & 0.09 \\
\hline 15. Ability to evaluate radiological images ${ }^{t}$ & 0.0 & 10.0 & 5.0 & 7.0 & 8.0 & 6.32 & 2.17 & 0.34 \\
\hline 16. Ability to examine a patient & 5.0 & 10.0 & 8.0 & 8.0 & 9.0 & 8.15 & 1.13 & 0.14 \\
\hline 17. Ability to correlate clinical and radiological findings ${ }^{f}$ & 0.0 & 10.0 & 6.0 & 7.0 & 8.0 & 6.88 & 1.79 & 0.26 \\
\hline 18. Exceeding expectations for the sessions & 4.0 & 10.0 & 7.0 & 9.0 & 10.0 & 8.47 & 1.59 & 0.19 \\
\hline
\end{tabular}

\# Strong correlation between items 1 and 13 ( $\rho=0.75$, p-value $<0.001)$; $§$ Strong correlation between items 5 and $6(\rho=0.81$, p-value $<0.001) ; \mathrm{f}$ Strong correlation between items 15 and $17(\rho=0.73$, p-value $<0.001)$.

than the distribution of the scores of items "History-taking and physical examination understanding', "Degree of support of the sessions for the learning of semiology" and "Attention given by the teaching assistants when answering questions".

Among the possible 153 pairs of items, only 3 pairs showed a strong correlation. The strongest correlation ( was found between the items "Selection of clinical cases" and "Ability of the teaching assistants to integrate images with the patient's clinical findings", that is, the score of "How do you rate the selection of clinical cases to be presented" is strongly correlated to the score of "Ability of the teaching assistants to integrate images with the patient's clinical findings". The second strongest correlation ( was found between the items "Overall score" and "Level of satisfaction with the semiology-radiology sessions", that is, the overall score is strongly correlated to score of "Level of satisfaction with the semiology-radiology sessions". Another strong correlation ( was found between the items "Ability to evaluate radiological images" and "Ability to correlate clinical and radiological findings".

When asked for suggestions, students stated that sessions should be longer, allowing more time to group the students before the session begins, dividing the students into smaller groups to facilitate discussions, providing more workstations for access to and viewing PACS images, and inclusion of PACS image analysis in the Clinical Radiology course.

\section{DISCUSSION}

In Brazil, Semiology is a mandatory course in the fifth and sixth semesters of the medical curriculum. Lectures are often delivered to address the theoretical content of semiology courses in the current medical school teaching-learning scenario ${ }^{10}$. However, the role of this teaching model is changing from "information giver" to a "learning facilitator"11,12. Facing the need to advance the multidisciplinary approach, the present study evaluated the results of the integration of the Medical Semiology and Clinical Radiology courses for fifth-semester 
medical students, implemented at our institution.

Knowledge of radiology is essential for professional medical training, as it is used in nearly all specialties of medicine. The growing importance of imaging tests in the emergency setting, the need for early integrated radiology teaching in the medical curricula and the rapid development of new technologies have brought the radiologist out of the dark room to the patient's bedside ${ }^{13}$. Radiology teaching should no longer be isolated from clinical practice and from the patient-centered specialty-specific format of teaching, given that it seems to be essential for improving the understanding of images by medical students ${ }^{14,15}$. Ganske et al. $^{16}$, announced an increase in the use of digital methods and teaching of radiological anatomy. Rabbo et al. ${ }^{17}$ found that the integrated teaching of radiological and topographic anatomy enhanced students' interest and understanding of the practical applications of anatomy. Raja et al. $^{18}$, showed a definite increase in radiological anatomy in medical school curricula in the United Kingdom. According to Wentzell et al. ${ }^{19}$, a modest improvement in basic chest $x$-ray interpretation skills and confidence levels amongst first-year undergraduate medical students was demonstrated. Therefore, clinically-oriented radiology teaching is unavoidable to better prepare students for the real-life clinical environment.

Students showed a positive perception of this new type of methodology. In the present study, after attending integrated semiology-radiology teaching sessions, $80 \%$ of the students felt they were able to correlate clinical and radiological findings. Students also found that the semiology-radiology sessions contributed to the development of their clinical reasoning, as demonstrated by the high mean scores assigned to this item. We may assume that the sessions stimulated active learning based on the observed increase in interactivity, participation and engagement of students.

A significant obstacle to the development of radiology teaching is the radiologist's preference for working in their subspecialty over teaching ${ }^{20-23}$. Also, there is a wide variety of educational models, making it difficult to carry out national surveys to evaluate improvements in radiology education in medical schools ${ }^{24}$. Moreover, there is no cooperation among medical schools for the standardization, organization and implementation of diagnostic imaging teaching tools ${ }^{25}$. All these factors may be reflected in the students'reported difficulty in learning radiology at the beginning of their professional education in medical school ${ }^{20,26}$.

The students were able to simultaneously assimilate both semiology aspects and radiological imaging. In the present study, we observed an increased understanding of the significance of physical examination and signs/symptoms presented by the patient compared to the understanding of images, as demonstrated by the lower mean scores in the latter. A possible explanation is that our study sample of students had minimal experience in radiology, with no prior contact with the subject. Also, the radiological content is extensive and involves 3D-anatomy and multimodality imaging techniques, which are impaired by technical difficulties, such as large groups, short sessions and few PACS image analysis, workstations, as pointed out by our participants, and the small workload available for this activity.

The integration of radiology and semiology teaching is necessary in order to encompass the complexity inherent to radiological image interpretation. According to Chew et al. ${ }^{27}$ almost all pathological conditions have a radiological manifestation that can be used to diagnose it, indicating that Radiology should be used as a teaching tool for clinical reasoning. The effectiveness of the semiology-radiology model is shown by the association between the students' ability to correlate clinical and radiological findings and their satisfaction with the semiology-radiology practical sessions, i.e., students who considered this a good teaching technique also considered themselves able to incorporate concepts and skills from the two disciplines into their practice. The high overall score and high level of satisfaction with the teaching sessions were also positive outcomes. We believe that the switch from the teacher (in this case, teaching assistants) as an information provider to one of a guide and a stimulator was one of the reasons for such good results. Also, differential diagnoses were discussed as well, helping students to broaden their understanding of many factors, which can influence their interpretation of clinical features and radiological findings. Considering that it is realistically impossible to know as many as 60,000 diagnoses and 6,000 treatments and to keep up with the new discoveries that are being made on an ongoing basis, this new teaching strategy seems appropriate in that it will engage students and improve their attention, making students more critical thinkers and wiser and more attentive observers ${ }^{28}$.

During the extra-class activities, an interesting point observed was the students' preference for the visualization of magnetic resonance images and reconstructed computed tomography images in thecoronal plane.Thisform of visualization, associated with remarkable semiological lesions, such as a bulky abdominal mass, ascites, and hepatosplenomegaly, was considered a learning facilitator, because it can be readily associated to the bedside anatomy and physical examination. Another observation was that the organization of students in small groups for the sessions made them feel more comfortable asking questions than if they were in a larger group or in class, as it is done in classic radiology teaching.

Another factor that helped the teaching-learning 
process was the students' great interest in learning how to use the PACS and the possibility of comparing pre-test and posttest results for the clinical case under consideration. Advances in technology and PACS probably demonstrate living anatomy and clinical pathology in details to students in improved ways. We attribute the students' interest in digital files to the fact that they seem arranged in a way that is similar to that of the applications students have on their smartphones and tablets, organized by date, test modality, and patient care unit (emergency department, outpatient clinic, or ward).

Thus, as artificial intelligence and e-Learning grows, new approaches to undergraduate Radiology teaching are increasing. It is important to clarify that, despite the recent development of technologies, touch, auscultation, percussion, and feeling are irreplaceable and integrated teaching semiology-radiology will not replace the personal interactions with patients in a real-world hospital and outpatient care setting.

Some limitations of this study comprised the technical difficulties such as large groups, few PACS image analysis workstations, the insufficient number of tutors and time for extra-class activities, and that the effects of the activities were not assessed on the students' competence in a real or simulated scenario. Therefore, a large cohort should be analyzed to provide representative information and further studies are needed to improve the understanding of the integration of radiology and semiology teaching in order to encompass the complexity of the topic.

\section{CONCLUSIONS}

Medical schools and university hospitals are facing new challenges and opportunities regarding the teaching of radiology. New technologies and innovative approaches may help imparting radiology knowledge and skills to medical students. For the integrated curricula with their studentcentered and problem-based teaching methods, Radiology coupled with Semiology training could be an innovative and promising practical way of teaching students.

The integration of radiology teaching into the semiology course demonstrated in this study has provided a novel teaching method for medical students by providing critical thinking skills for interpreting radiological images relative to clinical cases, thus arousing students' interest and probably facilitating their learning. Maybe Radiological and Semiology integrated teaching, as it seems to be, could be another successful future learning tool.

\section{AUTHORS' CONTRIBUTION}

Rafaela Queiroz de Morais: data curation; methodology; writing of the original draft. Luciana Thurler Tedeschi: formal analysis; validation; software; writing of the original draft. Cristina Asvolinsque Pantaleão Fontes, Marcia Maria Sales dos Santos and Maria Auxiliadora Nogueira Saad: study concept, data curation; investigation; methodology; project administration; supervision; manuscript writing, review and editing.

\section{CONFLICTS OF INTEREST}

None.

\section{SOURCES OF FUNDING}

This research did not receive any specific grant from funding agencies in the public, commercial, or not-for-profit sectors.

\section{REFERENCES}

1. Aquino LA, Wuillaume SM, Cardoso MHCA. Ordering in time and in space: narrative epistemology, semiology and clinical reasoning. Rev Bras Educ Med. 2012;36(1):100-8.

2. Loewe R. Narrative based medicine: dialogue and discourse in clinical practice. Literature and Medicine, Volume 19, Number 2, Fall 2000, pp. 288-92.

3. Mota A, Schraiber LB, Ayres JRCM. The "Paulista way"; building collective health in the state of São Paulo, Brazil. Interface. 2017;21(60):5-11.

4. Guedes CR, Nogueira MI, de Camargo Junior KR. Subjectivity as anomaly: epistemological contributions for a criticism of the biomedical model Cienc Saúde Colet. 2006;11(4):1093-103.

5. Vaughn L, Baker R. Teaching in the medical setting: Balancing teaching styles, learning styles and teaching methods. Med Teach. 2001;23(6):610-2.

6. Frenk J, Chen L, Bhutta ZA, Cohen J, Crisp N, Evans T, et al. Health professionals for a new century: Transforming education to strengthen health systems in an interdependent world. Lancet. 2010;376(9756):1923 58. doi: 10.1016/S0140-6736(10)61854-5.

7. Dochy F, Segers M, van den Bossche P, Gijbels D. Effects of problem-based learning: A meta-analysis. Learn Instr. 2003;13(5):533-68.

8. European Society of Radiology (ESR). ESR statement on new approaches to undergraduate teaching in Radiology Insights Imaging. 2019;10(1):109. doi: 10.1186/s13244-019-0804-9.

9. Dancey C, Reidy J. Statistics without maths for psychology: using SPSS for Windows. Bergen County, NJ: Prentice Hall, 2004.

10. Midão CMV, Ruiz-Moreno L. Teaching the medical semiology at medical schools in the state of Rio de Janeiro. Rev Bras Educ Med. 2010;34(3):397-405.

11. Hamdy H. Medical college of the future: from informative to transformative. Med Teach. 2018;40(10):986-9.

12. Mezrich JL. Innovative teaching methods in radiology - building on the experiences of other disciplines. Acad Radiol. 2019;26(1):116-7.

13. Slanetz PJ. Vital signs in radiologic education. Acad Radiol. 2018;25(6):685-6

14. Nacif MS, Siqueira-Batista $R$, Torres A. Teaching and research in radiology and diagnostic imaging in the undergraduate medical course: an interdisciplinary perspective. Rev Cienc Ideias. 2001;3(1):1-9.

15. Sheng M, Shah P, Choi JM, Gillis E, Katz SI, Simpson SA, et al. Patientcentered and specialty-specific case work-up: an effective method for teaching appropriateness of imaging to medical students. Acad Radiol. 2019;6:1-5.

16. Ganske I, Su T, Loukas M, Shaffer K. Teaching methods in anatomy courses in North American medical schools the role of radiology. Acad Radiol 2006;13(8):1038-46

17. Rabbo FA, Garrigues F, Lefèvre C Seizeur R. Interactive anatomical teaching: Integrating radiological anatomy within topographic anatomy. Morphologie. 2016;100(328):17-23. 
18. Sadler TJ, Zhang T, Taylor HL, Brasset C. The role of radiology in anatomy teaching in UK medical schools: a national survey. Clin Radiol. 2017;73:18590.

19. Wentzell S, Moran L, Dobranowski J, Levinson A, Hanningan A, Dunne $C P$, et al. E-learning for chest $x$-ray interpretation improves medical student skills and confidence levels. BMC Med Educ. 2018;18(256):2-8.

20. Gunderman RB, Siddiqui $A R$, Heitkamp DE, Kipfer HD. The vital role of radiology in the Medical School Curriculum. Am J Roentgenol. 2003;180(5):1239-42.

21. Kourdioukova EV, Valcke M, Derese A, Verstraete KL. Analysis of radiology education in undergraduate medical doctors training in Europe. Eur $J$ Radiol. 2011;78(3):309-18.

22. Bhogal P, Booth TC, Phillips AJ, Golding SJ. Radiology in the undergraduate medical curriculum - who, how, what, when, and where? Clin Radiol. 2012;67(12):1146-52.
23. Cohen MD, Gunderman RB, Frank MS, Williamson KB. Challenges facing radiology educators. J Am Coll Radiol. 2005;2(8):681-7.

24. Pascual TNB, Chhem R, Wang SC, Vujnovic S. Undergraduate radiology education in the era of dynamism in medical curriculum: an educational perspective. Eur J Radiol. 2011;78(3):319-25.

25. Chojniak R, Carneiro DP, Simonetto G, Moterani P, Muglia VF, D’Ippolito G. Mapping the different methods adopted for diagnostic imaging instruction at medical schools in Brazil. Radiol Bras. 2016;50(1):32-7.

26. Harden RM. Ten key features of the future medical school - not an impossible dream. Med Teach. 2018;40(10):1010-5.

27. Chew C, Cannon P, O'Dwyer PJ. Radiology for medical students (19252018): an overview. BJR Open 2020;1:1-6.

28. Sivarajah RT, Curci NE, Johnson EM, Lam DL, Lee JT, Richarson ML. A review of innovative teaching methods. Acad Radiol. 2019;26(1):101-3. 